\title{
Factors Affecting the Performance of Chemically Amplified DUV Positive Photoresists
}

\author{
James W. Thackeray, Theodore H. Fedynyshyn, Angelo A. Lamola, Richard D. Small \\ Shipley Co. Inc., 455 Forest St. Marlboro, MA 01752
}

\begin{abstract}
This paper presents further results on two-component positive-tone chemically amplified DUV resist. A partially deblocked poly(p-vinyl)phenol film is shown to be stable to autocatalytic hydrolysis, unlike other blocked poly(p-vinyl)phenol films. The concept of 'T-top' formation through acid loss during the postexposure bake is presented as an additional concern, besides the well known base contamination effect. The activation energy for the deblocking reaction is measured to be $35 \mathrm{kcal} / \mathrm{mole}$ and the kinetic order for deblocking is 1.9. These resists show better linearity and exposure latitude at lower PEB temperatures such as $70^{\circ} \mathrm{C}$, with a resultant substantial photospeed penalty.
\end{abstract}

\section{Introduction}

The development of a stable, chemically amplified (CA), positive-tone deep ultraviolet (DUV) photoresist has been an important goal at many research centers in the world. 1 These resists have shown high resolution and high photospeed and they have great potential for use in lithography, if they can be made more process worthy. Environmental stability has been identified as a critical perfomance issue. 2,3 Attempts at controlling exposure to the environment, through the use of protective cover coats and/or environmental chambers, add difficulty and expense in a production environment.

The concept of chemical amplification, in which the generation of catalytic amounts of acid leads to many chemical events per unit acid produced, provides an avenue to high photospeed and lessens the power requirements of the exposure source. However, in order for chemically amplified systems to gain widespread acceptance in the lithographic community, many diverse and, in some cases, contradictory properties must be designed into the resist system. The first order requirements for the resist are environmental stability, good adhesion to many types of substrates, and limited shrinkage upon postexposure baking and plasma etching. The second order requirements for the resist are high resolution, wide process latitude, and good thermal and etch resistance. It is helpful, when developing these types of resists, to separate the achievement of the first order requirements from that of the second order requirements. This strategy was used in the development of Shipley Megaposit ${ }^{\circledR}$ SNR248 ${ }^{\mathrm{TM}}$ DUV resist, the first commercially available, stable, chemically amplified negative-tone resist. 4

This paper will report our further results on two-component deep UV positive resists with enhanced environmental stability. These resists have shown no evidence of 'T-top' formation over a five hour delay between exposure and postexposure bake, and no change in linewidth as well. 5 In this paper, we discuss the stability of the partially blocked poly(pvinyl)phenol to autocatalytic hydrolysis, a key criteria for overall resist reproducibility and product shelflife. We present acid loss as another potential mechanism for 'T-top' formation. We show that the kinetic order plot is a good measure of whether acid loss is occurring during the PEB step. Finally, we show that the lithographic response of these resists improve with lower PEB temperatures, albeit with a substantial photospeed penalty. 


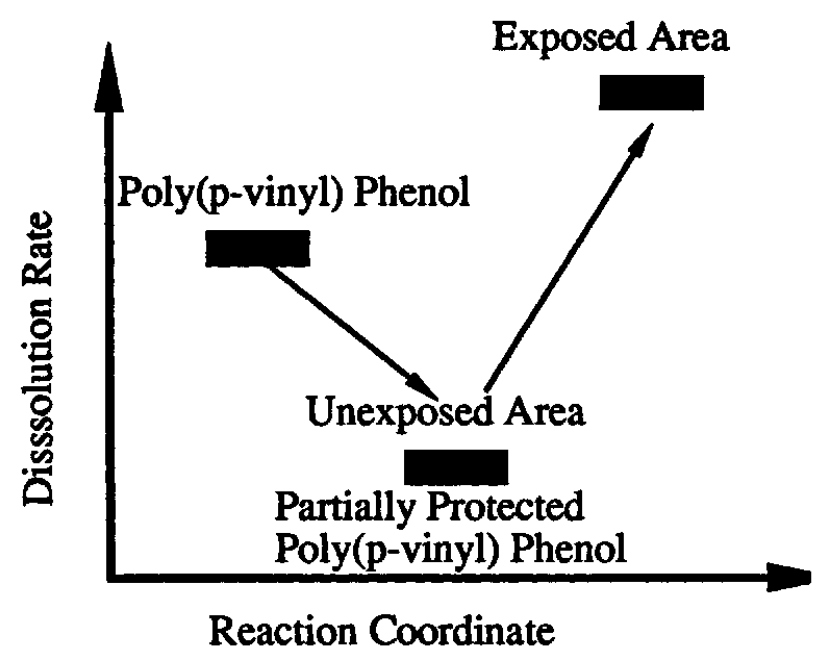

Figure 1. Inhibition/acceleration scheme for a two-component resist containing partially blocked poly(p-vinyl)phenol and a photoacid generator (PAG).

\section{Resist Chemistry}

We have investigated a 2-component approach to DUV positive resist development. Figure 1 shows the schematic reaction coordinate for 2-component resists investigated. For the 2component resists, we have partially blocked poly(p-vinyl)phenol in order to inhibit the polymer and then used photoacid generators which generate strong Bronsted acids to deprotect the polymer. Figure 2 shows the partially blocked polymer concept, where the $R$ group is acid labile at elevated temperatures. We have studied the partially deblocked polymer in order to determine whether the acidic function generated in the partially deblocked polymer can be autocatalytically deprotected. Figure 3 shows the dissolution rate of the partially blocked polymer as a function of softbake temperature. From 80 to $100^{\circ} \mathrm{C}$, the polymer film shows a steady decrease in dissolution rate, which is a classical response to solvent removal upon higher temperature softbakes. A gradual increase in dissolution rate is observed at $110^{\circ} \mathrm{C}$ followed by substantial increases in dissolution rate at $120^{\circ} \mathrm{C}$ and above. The increase in dissolution rate is due to thermal deblocking of the polymer. We have tested the stability of a partially deblocked polymer by baking a polymer film at $130^{\circ} \mathrm{C}$ for 5 minutes and measuring the dissolution rate as a function of storage time, and also after a $95^{\circ} \mathrm{C}$ postbake. Figure 4 shows the results of these experiments. Our data indicates that the partially deblocked polymer is not effective in causing autocatalytic deblocking. It is well known that the trimethylsilyl group can be autocatalytically hydrolyzed from partially blocked poly(p-vinyl)phenol. 14 Stability to autocatalytic hydrolysis is important because the shelflife of a resist could be negatively impacted by hydrolysis reactions in the bottle. It is also important to determine whether the exposed resist can undergo hydrolysis over time thereby leading to photospeed shifts after exposure. 6 


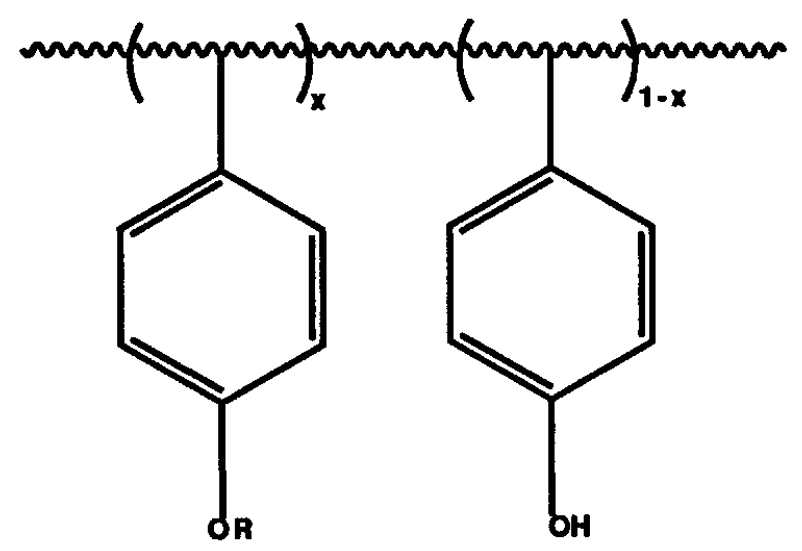

Figure 2. Partially protected phenolics, where $R$ is an acid labile group, exhibit sufficient transparency, inhibition capability, and free phenolic hydroxyl sites for use in positive-tone DUV resists.

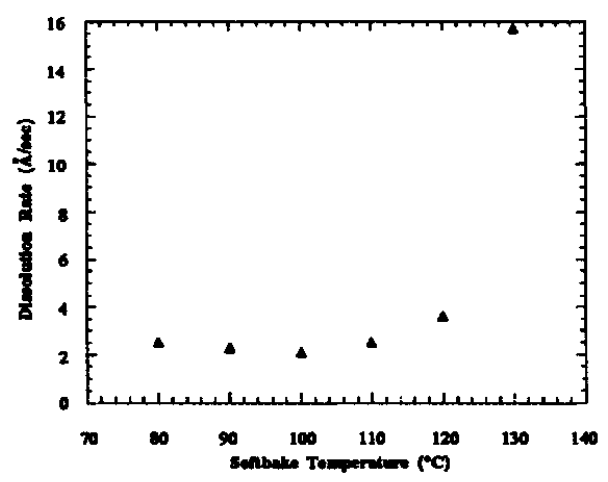

Figure 3. Dissolution rate vs. softbake for a partially blocked poly(p-vinyl)phenol film. All softbake times were 300 seconds. Development in XP-89114 at $21^{\circ} \mathrm{C}$.

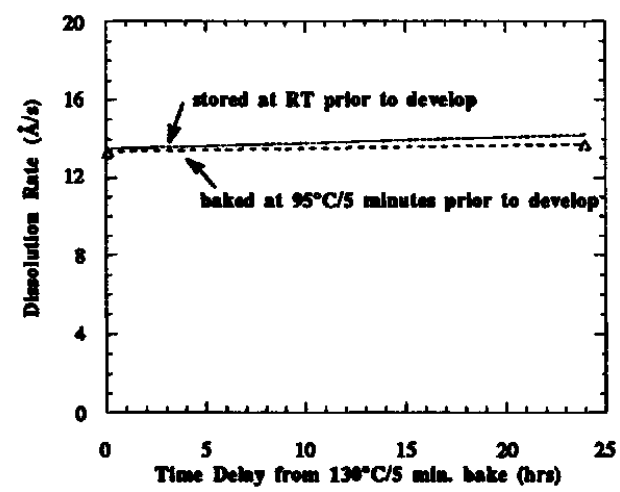

Figure 4. Dissolution rate of partially deblocked poly(p-vinyl)phenol coated films that have been baked at $130^{\circ} \mathrm{C}$ for 300 seconds initially. Development in XP-89114 at $21^{\circ} \mathrm{C}$. 
The photoacid generators that we investigated are outlined in Figure 5. The acid generators are classified as follows: Crivello salts 7 , sulfonate esters 8,9 , and halogen-containing compounds. 10 For positive-tone CA resists, our major efforts have been focussed on nonionic photoacid generators. In every resist tried, the Crivello salts showed a marked tendency to environmental instability. As for the halogen-containing compounds, these acid generators only worked well in a limited set of systems. For all of these acid generators, careful consideration of the type of acid generated is required. Because the acids generated can be volatile (i. e. $\mathrm{HBr}$ ), and can be classified in some cases as superacids (i. e. $\mathrm{HAsF}_{6}$ ), there are two routes to 'T-tops' that are possible, as shown in Figure 6: the first route is the loss of acid during the post-exposure bake process, leading to acid depletion, and the second route is through the introduction of basic environmental contaminants into the resist. We believe that a narrow window exists in the choice of photoacid generators which do not suffer from these two problems. Much work has been done on the effect of environmental contaminants on CA positive resists, but relatively little work has been reported on potential acid loss from the resist during the PEB step.<smiles>[R]OS(=O)(=O)Oc1cccc(OS(=O)(=O)O[R])c1OS(=O)(=O)O</smiles>

Where $R=$ Me, Et, Pr, Phenyl, etc.

[1]<smiles>[X][W]#[W]c1ccccc1</smiles>

Where $n=2,3 ; M=1, S$; and $\mathrm{X}=\mathrm{ASF}_{6}, \mathrm{CF}_{3} \mathrm{SO}_{3}$

\section{[ 2 ]}

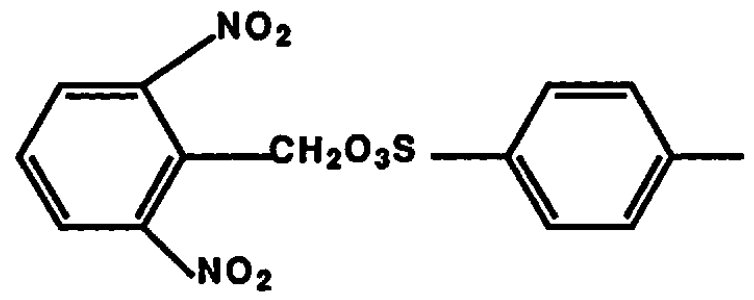

[ 3 ]<smiles>CC(C)([Mg])c1ncncn1</smiles>

Figure 5. Three classes of photoacid generators have been investigated. The first class, sulfonate esters ([1] and [3]); the second class, onium salts ([2]); and, finally, the third class, halogen containing compounds ([4]). 


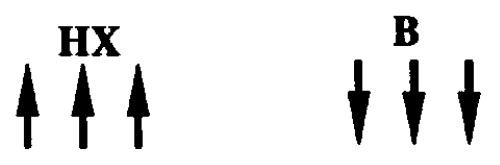

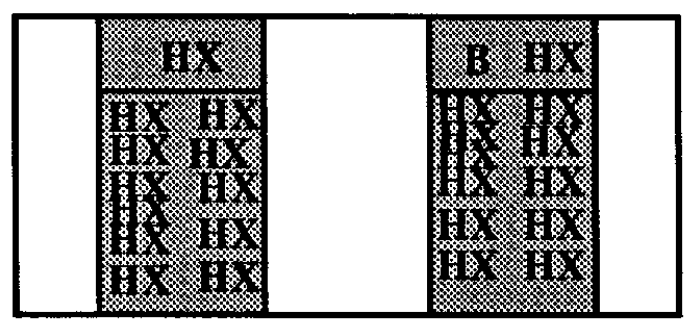

(a.)

(b.)

Figure 6. Schematic representation of two modes of 'T-top' formation, (a.) where the acid is baked out of the film during the PEB step; and (b.) where the acid is neutralized by environmental basic contaminants.

\section{Resist_Processing_Issues}

As with all chemically amplified resists, careful consideration of processing conditions for the positive resists must be made. In our previous paper on CA positive resists, we reported on our initial promising results with regard to resist stability without the need of a covercoat. In this section, we will discuss a newer version CA positive-tone resist in which we have changed the PAG.

Figure 7 shows the contrast curves for a two-component resist as a function of PEB temperature. As expected, the photospeed increases with increasing PEB temperature. In this system, it appears that the contrast increases with PEB temperature as well. The resist shown in Figure 7 has an $\mathrm{E}_{\mathrm{O}}$ of $45 \mathrm{~mJ} / \mathrm{sq} . \mathrm{cm}$. using the $75^{\circ} \mathrm{C} / 5$ minute postexposure bake condition. For this resist system, XP89114 developer (0.14 N) was used.

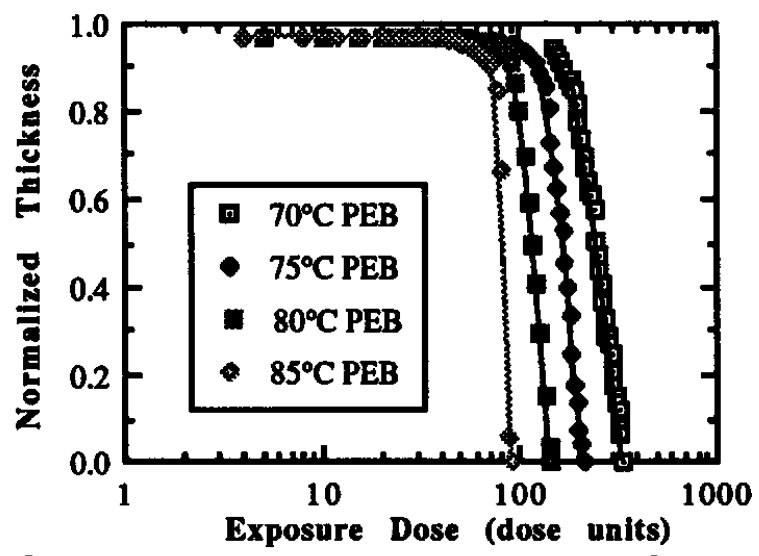

Figure 7. Contrast curves vs. PEB temperature for a new 2-component positive DUV resist. All wafers exposed on a $0.35 \mathrm{NA}$ excimer laser stepper where 100 dose units $\sim 30$ $\mathrm{mJ} / \mathrm{sq} . \mathrm{cm}$. 
We have applied the Seligson-Das model for chemically amplified resist systems to our 2component positive DUV resist system. In earlier studies, they showed that an acid hardened resist, SAL601-ER7, exhibited reciprocity for PEB time and temperature as measured by the photospeed response of the resist. 10 We have applied their rate equation, equation (1), to our positive resist system:
(1) $\mathrm{D}_{\text {eff }}=$
$D e^{-E a / R T}(t){ }^{1 / m}$

where $D_{\text {eff }}$ is the normalized sensitivity of a chemically amplified resist when $E_{a}$ and $m$ are constant, $D$ is the measured sensitivity, $E_{a}$ is the activation energy over a given PEB temperature range, $R$ is the gas constant, $T$ is the PEB temperature, $t$ is the PEB time, and $m$ is the kinetic order. If $E_{a}$ and $m$ are constant over a wide PEB processing regime, this equation has predictive value for photospeed as evidenced in the AHR resist systems.

Figure 8 shows an Arrhenius plot for sensitivity vs. PEB temperature, using a 300 second postexposure bake time. The activation energy is $39 \mathrm{kcal} / \mathrm{mole}$. The activation energy of the AHR resists have been shown to be less than $10 \mathrm{kcal} / \mathrm{mole} .11$ Figure 9 plots the sensitivity vs. PEB time at $90^{\circ} \mathrm{C}$ PEB temperature. A kinetic order analysis, using equation (1), shows that the kinetic order is 1.9 at $90^{\circ} \mathrm{C}$. Note that these values for $\mathrm{Ea}$ and $\mathrm{m}$ are quite different than earlier reported for an earlier version of this resist. $5 \mathrm{We}$ attribute the higher activation energy and lower kinetic order to the change in PAG, the PAG being less volatile in this resist and thereby reducing acid loss as a mechanism of deactivation.

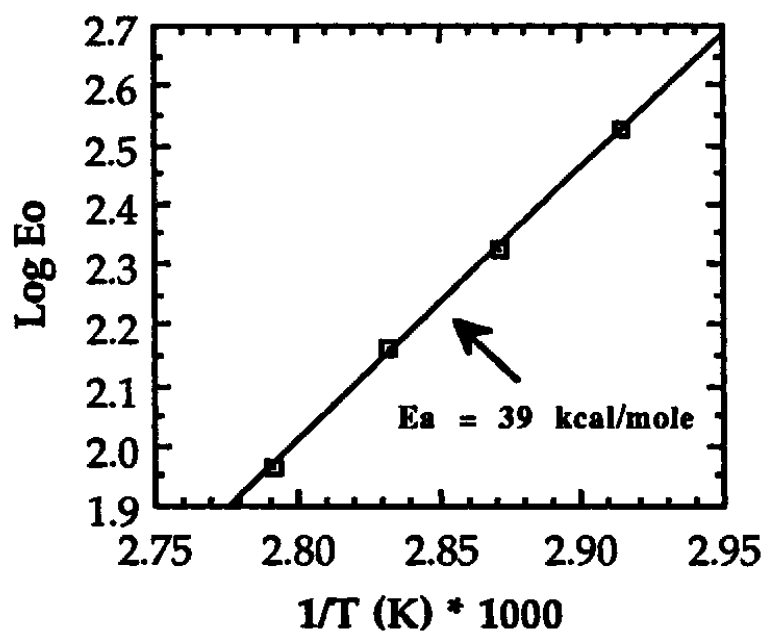

Figure 8. Arrhenius plots of photospeed vs. PEB temperature based on the data in Figure 7. 


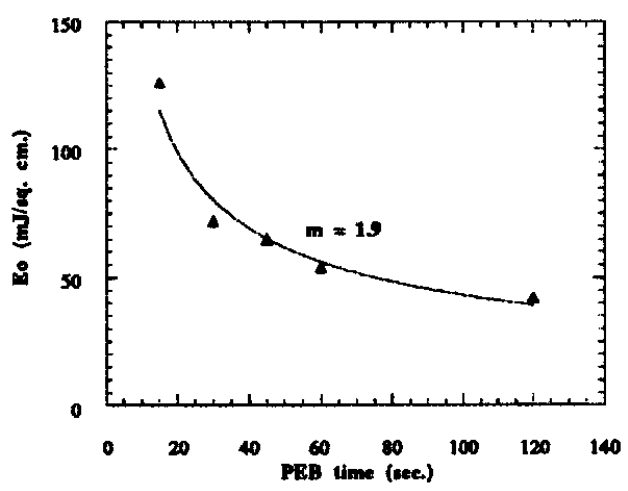

Figure 9. Kinetic order analysis of the 2-component resist, where postexposure bake temperature is $90^{\circ} \mathrm{C}$.

Figure 10 shows imaging of $0.5 \mu \mathrm{m}$ lines and spaces for the 2-component resist as a function of PEB temperature. With this resist, profile, $C D$ bias, linearity, and exposure and focus latitude all improve markedly with lower PEB temperatures. The SEM micrographs indicate that the resist suffers from a 'T-top' problem at higher PEB temperatures which can be explained by acid depletion during the PEB step. We assume that acid loss is the probable cause for the 'T-top' at higher PEB temperatures for two reasons: 1.) a patterned DUV-exposed wafer can transfer the pattern to an unexposed wafer that is placed face down on the exposed wafer during the PEB step, and 2.) because these resists show good environmental stability over a five hour time period 5 , which would tend to rule out environmental contamination as a problem. Further work on distinguishing these acid loss mechanisms is critical to the development of robust DUV positive resists. Of course, the option of using lower PEB temperatures is a possible solution with substantial loss in photospeed.

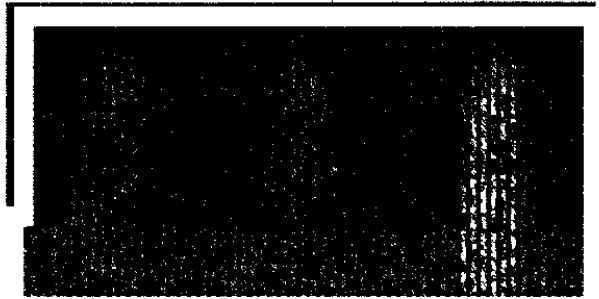

(a)

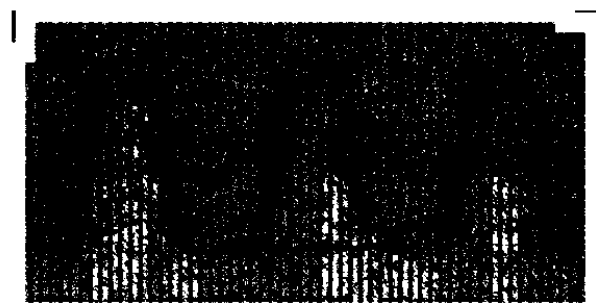

(b)

Figure 10. SEM micrographs of $0.5 \mu \mathrm{m}$ lines and spaces at (a) $70^{\circ} \mathrm{C}$, where the $\mathrm{E}_{\text {size }}=$ $450 \mathrm{~mJ} / \mathrm{sq}$. cm., and, (b.), $90^{\circ} \mathrm{C}$, where the $E_{\text {size }}=59 \mathrm{~mJ} / \mathrm{sq} . \mathrm{cm}$. Exposures done on a 0.44 NA excimer laser stepper 
Figure 11 shows the linearity plot for lines and spaces for this two-component photoresist. We obtain linearity to $0.40 \mu \mathrm{m}$ for gratings, with virtually no $\mathrm{CD}$ bias between gratings and isolated lines. The linearity and $\mathrm{CD}$ bias worsens with higher PEB temperatures. The exposure latitude for this resist at $70^{\circ} \mathrm{C}$ and $90^{\circ} \mathrm{C}$ is shown in figure 12 . The drastic loss in exposure latitude is evident at the higher PEB temperature. Note that the $\mathrm{E}_{\text {size }}$ increases from $59 \mathrm{~mJ} / \mathrm{sq}$. cm. at a $90^{\circ} \mathrm{C} \mathrm{PEB}$ to $450 \mathrm{~mJ} / \mathrm{sq}$. cm. at a $70^{\circ} \mathrm{C} \mathrm{PEB}$ temperature.

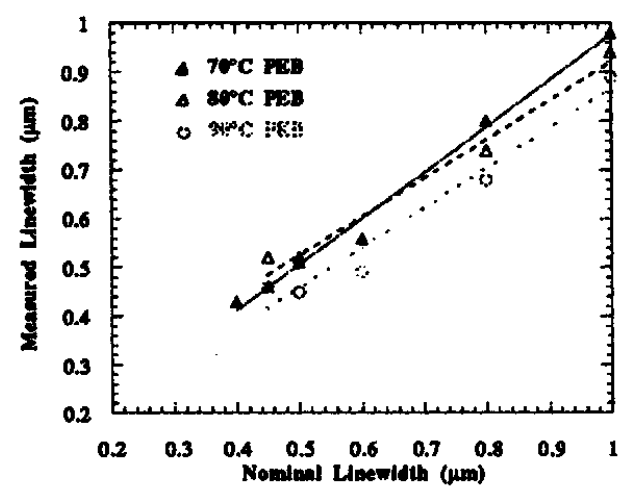

Figure 11. Linearity of the 2-component resist as a function of PEB temperature

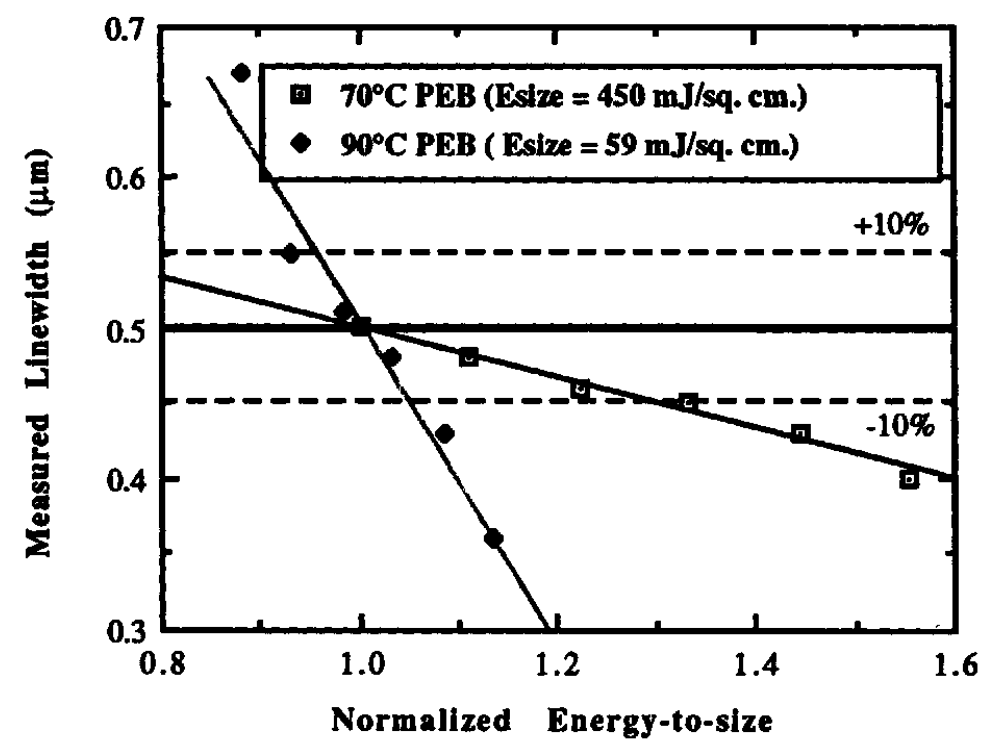

Figure 12. Exposure latitude of the 2-component resist as a function of PEB temperature. 


\section{Conclusions}

This paper has demonstrated the viability of a stable, positive-tone, chemically amplified photoresist for DUV applications. There remain many critical areas for improvement and understanding of these types of resist materials. We have shown that the partially deblocked polymer does not suffer from autocatalytic deblocking upon storage for a 24 hour period. We have discussed two routes to 'T-tops': the first route can be through acid loss at the resist/air interface during the PEB step, and the second route through the introduction of basic environmental contaminants. There exists a narrow window for photoacid generators that do not suffer from either of these problems. We have also shown that the resist performance improves markedly at low PEB temperatures, with an attendent photospeed penalty. Our future work will focus on methodologies to increase photospeed and increase the process latitude for these resists.

\section{Acknowledgements}

We wish to acknowledge the Microelectronics Center of North Carolina and SEMATECH (Austin, TX) for providing us with access to their clean room facilities and the opportunity to expose many cassettes of wafers on the excimer laser steppers housed in both facilities.

\section{References}

1. For a review of chemically amplified resists, see: A. A. Lamola, C. R. Szmanda, J. W. Thackeray, "Chemically Amplified Resists," Solid State Technology, 8, 53 (1991).

2. (a) O. Nalamasu et al,"Preliminary Lithographic Characteristics of an All-organic Chemically Amplified Resist Formulation for Single Layer Deep-UV Lithography," Proc. SPIE, 1466, 13 (1991); (b.) O. Nalamasu et al, "Development of a Chemically Amplified Positive (CAMP) Resist Material for Single Layer Deep-UV Lithography," Proc. SPIE, 1262,32 (1990).

3. S. A. MacDonald et al, "Airborne Chemical Contamination of a Chemically Amplified Resist", Proc. SPIE, 1466, 2 (1991).

4. (a.) J. W. Thackeray, G. W. Orsula, M. M. Rajaratnam, R. Sinta, D. Herr, E. K. Pavelchek, "Dissolution Inhibition Mechanism of ANR Resists: Crosslinking vs. -OH Site Consumption," Proc. SPIE, 1466, 39 (1991); (b.) J. W. Thackeray, G. W. Orsula, E. K. Pavelchek, D. Canistro, L. E. Bogan, A. K. Berry, K. A. Graziano, "Deep UV ANR Photoresists for $248 \mathrm{~nm}$ Excimer Laser Photolithography," Proc. SPIE, 1086, 34 (1989).

5. J. W. Thackeray, D. Canistro, M. Denison, J. Ferrari, R. Hemond, D. Medeiros, G. W. Orsula, E. K. Pavelchek, M. Rajaratnam, R. Sinta, "Toward the Development of a Stable, Chemically Amplified DUV Positive Photoresist," Proc. SPIE, in press.

6. H. Oertel et al, "Resist Modeling near Resolution and Sensitivity Limits in X-ray Lithography," Proc. SPIE, 1089, 283 (1989).

7. (a.) J. V. Crivello, "UV Curing: Science and Technology," S. P. Pappas, ed., Technology Marketing Corp., Stamford, CT, 1978, 23; (b.) H. Ito, C. G. Willson, Polym. Eng. Sci., 23, 1012 (1983). 
8. (a.) L. Schlegel, T. Ueno, H. Shiraishi, N. Hayashi, T. Iwayanagi, "Acid Formation and Deprotection Reaction by Novel Sulfonates in a Chemical Amplification Positive Photoresist," Chem. Mater., 2, 299 (1990); (b.) L. Schlegel, T. Ueno, N. Hayashi, T. Iwayanagi, "Determination of Acid Diffusion in Chemical Amplification Positive Deep Ultraviolet Resists," J. Vac. Sci. Tech. B, 2(2), 278 (1991).

9. T. X. Neenan et al, "Chemically Amplified Resists: A Lithographic Comparison of Acid-generating Species," Proc. SPIE, 1086, 2 (1989).

10. W. E. Feely, U. S. Patent 5,034,304.

11. B. Kuyel, H. Sewell, "The Effects of Broadband 250nm Illumination on Process Latitude," J. Vac. Sci. Tech.,_B8(6), 1385 (1990).

12. (a.) S. Das, D. Seligson, Proc. SPIE, "Photopolymers Principles- Processes and Materials," 1 (1988); (b.) D. Seligson, S. Das, H. Gaw, P. Panietta, "Process Control with Chemical Amplification Resists using DUV and X-ray Radaition," J. Vac. Sci. Tech, B6, 2303 (1988).

13. S. Das, J. Thackeray, M. Endo, J. Langston, H. Gaw, "A Systematic Investigation of the Photoresponse and Dissolution Characteristics of an Acid Hardened Resist," Proc. SPIE, 1262, 60 (1990).

14. "Protective Groups in Organic Synthesis," T. W. Greene, Wiley \& Sons, New York, NY 1981. 